\title{
Article \\ Flavonoids and Limonoids Profiles Variation in Leaves from Mandarin Cultivars and Its Relationship with Alternate Bearing
}

\author{
Cecilia Rodríguez Ceraolo ${ }^{1}$, Valeria Vázquez ${ }^{1}$, Ignacio Migues ${ }^{1,2}{ }^{\mathbb{D}}$, María Verónica Cesio ${ }^{1}$, Fernando Rivas ${ }^{3}$ \\ and Horacio Heinzen ${ }^{1, *}$
}

Citation: Rodríguez Ceraolo, C.; Vázquez, V.; Migues, I.; Cesio, M.V.; Rivas, F.; Heinzen, H. Flavonoids and Limonoids Profiles Variation in Leaves from Mandarin Cultivars and Its Relationship with Alternate Bearing. Agronomy 2022, 12, 121. https: / / doi.org/10.3390/ agronomy12010121

Academic Editor: Salvatore Camposeo

Received: 31 October 2021 Accepted: 2 December 2021 Published: 4 January 2022

Publisher's Note: MDPI stays neutral with regard to jurisdictional claims in published maps and institutional affiliations.

Copyright: (c) 2022 by the authors. Licensee MDPI, Basel, Switzerland. This article is an open access article distributed under the terms and conditions of the Creative Commons Attribution (CC BY) license (https:/ / creativecommons.org/licenses/by/ $4.0 /)$.
1 Grupo de Análisis Metabolómicos (GAMe), Laboratorio de Farmacognosia y Productos Naturales, Departamento de Química Orgánica, Facultad de Química, Universidad de la República, Montevideo 11800, Uruguay; cceraolo@fq.edu.uy (C.R.C.); valeria.svazquezp@gmail.com (V.V.); imigues@fq.edu.uy (I.M.); cs@fq.edu.uy (M.V.C.)

2 Graduate Program in Chemistry, Facultad de Química, Universidad de la República, Montevideo 11800, Uruguay

3 Programa Nacional de Investigación en Produccción Citrícola, Instituto Nacional de Investigación Agropecuaria (INIA), Salto 50000, Uruguay; cfrivas@inia.org.uy

* Correspondence: heinzen@fq.edu.uy

\begin{abstract}
Alternate bearing in citrus trees has been extensively studied as a key feature for citrus growers. Although the genetic and the biochemical process occurring during alternate bearing has been studied extensively, there is a lack of information identifying the presence of metabolic indicators during "on" and "off" years. In citrus plants, leaves play a central role in the metabolic pathway triggering the flowering induction process. To investigate the changes during this transition, a liquid chromatography coupled to tandem mass spectrometry (LC-MS/MS) analysis of the leaf profiles of 20 compounds (17 polyphenols, two limonoids, and one furanocoumarin), in bearing and non-bearing branches arising from four different mandarin genotypes, was performed. The same metabolites were found in all the genotypes at both stages: both limonoids and 11 polyphenols. Using these compounds, the chemotaxonomic differentiation between cultivars was assessed. The levels of flavanones and limonoids showed differences in both bearing stages and the transition from vegetative to flowering could be shown by the activation of the polyphenol biosynthetic pathway, from precursors like naringenin to metabolic end-points such as narirutin and polymethoxyflavones. Narirutin levels showed significant differences between both stages, suggesting it as a possible marker of the physiological status of the branch.
\end{abstract}

Keywords: polyphenols; limonoids; secondary metabolism; bearing branches; non-bearing branches

\section{Introduction}

Citrus is one of the main fruit crops worldwide with more than 143 million tons produced in 2019 [1]. Alternate bearing in Citrus is one of the major limiting factors affecting production profits and, thus, tackling the maximal potential benefits for the global citrus industry is essential. Therefore, the genetic, biochemical, and metabolic determinations of alternate bearing have been widely studied, aiming to gain knowledge about the regulatory process in the transition from bearing to non-bearing trees. However, the mechanism by which the developing crop influences blooming and fruit yield the forthcoming year has not been fully understood yet. One hypothesis holds that return bloom and yield are related to tree carbohydrate status and, thus, lack of carbohydrate in the "on" year directly or indirectly reduces flowering the following year [2]. Other authors claim that developing fruit produces an inhibitor that directly or indirectly reduces flowering in the spring following the "on" crop [2,3]. Although extensive research has been conducted to unravel the hormonal and genetic regulation of flowering induction in Citrus $[4,5]$, there is still a lack of information describing metabolites' changes (in terms of 
quality and quantity) occurring during "on" and "off" years as putative markers depicting this transition.

Flowering represents a transition phase from vegetative to reproductive growth and, thus, it is one of the most important events in the plant life cycle. During vegetative to reproductive transition, citrus undergoes metabolic regulations that have been extensively reported [6].

Flowering is regulated by endogenous and exogenous factors. The first one has been mainly attributed to the genetic and hormonal modulation of the LFY gen and Gibberellins metabolic pathway [7-9], identifying the fruit-mediated inhibition of flowering as the main cause of alternate bearing in citrus [10]. Similarly, carbon metabolism has also been reported to be involved in flower induction mediated by fruit presence in citrus [2]. Exogenous regulation of flowering has been mainly attributed to environmental stress factors including light intensity and wavelength, temperature, mineral and carbon nutrition, drought, low oxygen, crowding, root removal, and mechanical stimulation, as well as biotic stress factors such as infection by pests and pathogens [11-13].

A possible approach to find the metabolic changes involved in the process of alternate bearing is the study of the metabolome of the leaves in both stages. In this way, polyphenols and limonoids fulfill definite biological and ecological properties in plants [14]. As an example, when the carbon/nutrient ratio is high, photosynthesis is primarily diverted to the production of carbon-based metabolites such as phenolics $[15,16]$ and, thus, high levels of phenolics are associated with in-excess accumulation of leaf carbohydrates. In this way, phenyl-propanoid biosynthesis serves as an 'energy overflow' mechanism by diverting photosynthate and cellular reducing power into stable product pools [17], preventing further oxidative damage during photoinhibition caused by high carbohydrates accumulation in leaves [18].

Polyphenols are a remarkably diverse group of secondary products with a vast array of biological functions. They protect plants from different biotic and abiotic stress and act as unique UV filters, signal molecules, allopathic compounds, phytoalexins, detoxifying agents and antimicrobial defensive molecules [19]. They are classified in to two major classes: flavonoids and nonflavonoids. The latter include structurally simple molecules such as phenolic acids (hydroxybenzoic acids and hydroxycinnamic acids) and stilbenes, along with highly complex molecules such as stilbene oligomers, tannins, and lignans [20]. The former is the most studied class of polyphenols, sharing the same general C6-C3-C6 structure. The most abundant have a flavan nucleus, consisting of two aromatic rings (A and B) linked by a pyran ring (C). Differences in the location of the B-ring to C-ring linkage make it possible to distinguish between flavonoids (2-phenylbenzopyrans), isoflavonoids (3-phenylbenzopyrans), and neoflavonoids (4-phenylbenzopyrans). The first one is by far the most abundant group and may be further divided into 3-hydroxyflavonoids (flavonols, flavanols, anthocyanidins, and dihydroflavonols), and flavonoids without substituent at C3 (flavanones and flavones). The flavonoids may be among the most important aromatic compounds. In this regard, they are the most ancient and widespread of the polyphenols, synthesized even in mosses and ferns, and have a wide range of potent physiological activities [21].

Citrus limonoids (CLs) are a crowded family of polycyclic secondary metabolites found mostly in seeds, fruits, and peel tissues of citrus fruits, including lemons, limes, oranges (both sour and sweet), pummels, grapefruits, bergamots, and mandarins [22]. CLs are highly oxygenated and modified triterpenes classified as tetranotriterpenoids, found as both free aglycones and their corresponding $\beta$-D-glycosides. Up to date, about 55 limonoid aglycones and 18 limonoid glycosides were identified in Citrus. Limonin is the most abundant aglycone in most citrus species followed by Nomilin, and limonin glycoside is the most representative limonoid glycoside [23]. CLs possess a wide array of biological activities [23], and have been acknowledged as high anti-insect activity compounds, both by their toxicity and antifeedant properties [22,24-28]. They probably protect leaflets from insects during bud development, justifying their abundancy in young leaves and 
fruit [29]. The first studies of CLs originate on the attempt to find bitter compounds in citrus fruit [30-32], but few reports on the occurrence of CLs in citrus tree leaves are found.

Metabolomic research strategies can be faced by two distinct approaches, untargeted and targeted, each with their own inherent advantages and disadvantages. Untargeted metabolomics is the comprehensive analysis of all measurable analytes in a sample. Although it offers the opportunity for novel target compounds discovery, the importance of rare molecules can be underestimated [33]. In contrast, the targeted approach is the precise and quantitative measurement of the concentrations of a defined group of chemically characterized metabolites. Hypothesis-driven targeted experiments can go together with the risk of losing the real natural products that are responsible for an observed biological property. For targeted analysis, sample preparation is optimized for obtaining a defined group of natural products.

Seeking the identification of possible representative phytomarkers of the transition from "on" to "off" bearing, the profiling of polyphenols and limonoids in leaves from bearing and non-bearing branches was studied using a targeted metabolomic approach.

\section{Materials and Methods}

\subsection{Plant Material}

The study was carried out at the National Agricultural Research Institute (INIA) of Uruguay, in Salto Province ( $31^{\circ} 16^{\prime}$ S; $57^{\circ} 53^{\prime} \mathrm{W}$, altitude: $47 \mathrm{~m}$ ), on adult trees from cv. 'Ellendale' (Citrus reticulata Blanco), cv. 'Satsuma' (Citrus unshiu Marc.), cv. 'Willowleaf' (Citrus deliciosa Ten.), and cv. 'Page' (Citrus reticulata Blanco $\times$ Citrus paradisi Macf.) grafted onto Poncirus trifoliata (L.) Raf. rootstock, under accurate horticulture cares (irrigation and pest management). From each variety, five bearing and five non-bearing trees were sampled. Adult leaves between 6 and 12 months old ( 5 leaves/branch; 10 branches sampled) were collected from bearing (B) and non-bearing (NB) branches. In bearing branches, leaves were collected immediately below the fruits $(5-20 \mathrm{~cm}$ from the peduncle) during full fruit color stage, whereas in non-bearing branches, leaves were selected to have the same characteristics and position as in bearing branches. All trees were located in the same orchard and growing conditions. Therefore, the differences in the composition between the varieties could not be ascribed to changes in the tree environment, but due to the genetic background and physiological state of each tree. In all the branches for sampling, leaves were taken randomly all around the outer part of the tree canopy, exposed to full sunlight, and immediately stored at $-20^{\circ} \mathrm{C}$ until extraction.

\subsubsection{Reagents and Equipment}

All mobile phases were prepared using High Performance Liquid Chromatographygrade solvents, supplied by Merck KGaA (Darmstadt, Germany), as well as analytical grade solvents used for extraction. Ultrapure water (Millipore Milli- ${ }^{\circledR}{ }^{\circledR}$ Ultrapure Water Solutions Type 1 by Merckmillipore, Molsheim, France) was used for the extraction and HPLC analysis. All standards were selected based on previous studies of flavonoid content in mandarins [34] and purchased from PhytoLab GmbH \& Co.KG (Vestenbergsgreuth, Germany).

Polyphenols and limonoids were analyzed in an Agilent 1200 LC system (Agilent Technologies, Palo Alto, CA, USA) coupled to a 4000 QTRAP ${ }^{\circledR}$ LC-MS / MS System from AB SCIEX $^{\mathrm{TM}}$ (Framingham, MA, USA). LC-Separation was performed on a Gold Aq-Hypersil $(5 \mu \mathrm{m} 150 \times 4.6 \mathrm{~mm})$ column from Thermo Scientific ${ }^{\mathrm{TM}}$ (USA). The injection volume was $5 \mu \mathrm{L}$. MS/MS detection was performed in the multiple reaction monitoring (MRM) mode using an electrospray ionization (ESI) interface in both positive and negative ion mode.

\subsubsection{Standard Solutions Preparation}

Individual standard solutions of the target compounds were prepared and stored at $-20{ }^{\circ} \mathrm{C}$. Each standard was weighed to approximately $20 \mathrm{mg}$ and dissolved in $10.00 \mathrm{~mL}$ of HPLC-grade methanol, to obtain a $2000 \mathrm{mg} / \mathrm{L}$ stock solution. A working solution mix of all targeted compounds $(20 \mathrm{mg} / \mathrm{L})$ was prepared by appropriate dilution of the stock solutions 
in acetonitrile and used for the calibration curve construction. The selected concentrations for the curve were 10, 50, 100, 200, 400, 600, 800, 1000, and $1500 \mu \mathrm{g} / \mathrm{L}$.

\subsubsection{Sample Preparation}

The extraction procedure for mandarin leaves was performed using an Ultrasoundassisted extraction (UAE) adapted from Safdar M.N. et al. [35]. A total of $50 \mathrm{~g}$ of freeze-dried leaves was pool together and ground using a cut mill for each variety. Then, $1 \mathrm{~g}$ of the powdered leaf samples was extracted with methanol $80 \%$ in a sample/solvent ratio 1:10 for $15 \mathrm{~min}$ in an Ultrasound bath (Transsonic 460; Elma, Wetzikon, Switzerland) at $35 \mathrm{kHz}$ frequency. This procedure was repeated twice using fresh solvent. The extracts were combined and subjected to bulk filtration, solvent vacuum evaporation, and lyophilization, followed by redissolution in $80 \%$ methanol HPLC grade and filtration through $0.22 \mu \mathrm{m}$ Polyvinylidene fluoride (PVDF) filters.

\subsubsection{Chromatographic and MS/MS Conditions}

The mobile phase was ultrapure water with $0.1 \%$ formic acid (A) and acetonitrile (B), with the subsequent gradient: $0-23 \mathrm{~min} 5 \%$ to $50 \% \mathrm{~B}, 23-26 \mathrm{~min} 50 \%$ to $100 \% \mathrm{~B}, 26-31100 \%$ $\mathrm{B}, 31-33 \mathrm{~min} 100 \%$ to $5 \% \mathrm{~B}, 33-385 \% \mathrm{~B}$, at $600 \mu \mathrm{L} / \mathrm{min}$. The ionization voltage was $5000 \mathrm{~V}$, the nebulizer and the curtain gases were nitrogen at 50 psi each. The solvent evaporation in the source was assisted by a drying gas (heated nitrogen at $500{ }^{\circ} \mathrm{C}$ per $50 \mathrm{psi}$ ).

A multiple reaction monitoring (MRM) mode method was used for quantification. The optimal MRM transitions, collision energies (CE), and declustering potentials (DP) for each investigated compound were determined infusing the standard solutions directly into the instrument at a constant flow, using a syringe.

\subsubsection{Data Treatment}

The statistical treatment was performed using Metaboanalyst 5.0 [36] and R-Studio software package (version 1.1.463). Each of the studied compounds were considered as a single variable and were included in all the treatments. Data were normalized using pareto scaling. ANOVA, Wilcoxon/Mann-Whitney, and multiple comparisons test using a Bonferroni correction were performed. Principal component analysis (PCA) and the supervised test partial least squares discriminant analysis (PLS-DA) were used for the classification of the varieties. The latter was validated to avoid overfitting using crossvalidation and permutation test. Heatmap based on Student's t-test was also performed.

\section{Results and Discussion}

\subsection{Optimization of MS/MS Parameters of the Target Compounds}

The acquisition method was ESI positive for limonoids and polymethoxyflavones, and negative for flavanones, flavone, and flavonols (Table 1). The chromatogram of the optimized compounds is shown in Supplementary Materials.

\subsection{Identification and Quantification of Phytochemicals in Leaves}

A total of 11 polyphenols were identified and quantified among the four genotypes, together with two limonoids. The identified phytochemicals were the flavanones didymin, eriocitrin, naringenin, hesperidin, and narirutin; two polimethoxyflavones, tangeretin and nobiletin; a flavonol, quercitrin, and the flavone luteolin, as well as the hydroxycinnamic acids chlorogenic and caffeic acid and the limonoids limonin and nomilin (Figure 1). The chromatogram of the identified compounds is shown in Supplementary Materials. 
Table 1. Results of optimization parameters for each evaluated compound.

\begin{tabular}{|c|c|c|c|c|c|c|c|c|}
\hline Analyte & {$[\mathrm{M}-\mathrm{H}]^{-}$} & {$[\mathrm{M}-\mathrm{H}]^{-} \rightarrow \mathrm{m} / \mathbf{z}$} & DW & DP & EP & $\mathrm{CE}$ & CXP & Rt (min) \\
\hline \multirow[t]{2}{*}{ Protocatechuic acid } & 153 & 108.8 & 150 & -40 & -10 & -22 & -15 & 9.4 \\
\hline & & 90.7 & 150 & -40 & -10 & -42 & -1 & \\
\hline \multirow{2}{*}{ Chlorogenic acid } & 353.7 & 190.8 & 150 & -50 & -10 & -24 & -31 & 11.1 \\
\hline & & 84.7 & 150 & -50 & -10 & -68 & -9 & \\
\hline \multirow[t]{2}{*}{ Caffeic acid } & 179 & 133.3 & 150 & -45 & -10 & -40.7 & -21.1 & 12.7 \\
\hline & & 88.7 & 150 & -45 & -10 & -48 & -14.1 & \\
\hline \multirow[t]{2}{*}{ Eriocitrin } & 595.2 & 286.6 & 150 & -80 & -10 & -38 & -9 & 14.5 \\
\hline & & 134.6 & 150 & -80 & -10 & -90 & -19 & \\
\hline \multirow{2}{*}{ Narirutin } & 579.2 & 150.5 & 150 & -95 & -10 & -75 & -20.3 & 15.9 \\
\hline & & 270.8 & 150 & -95 & -10 & -39.9 & -8.4 & \\
\hline \multirow[t]{2}{*}{ Naringin } & 579.2 & 270.8 & 150 & -105 & -10 & -54 & -7 & 16.3 \\
\hline & & 150.7 & 150 & -122.03 & -10 & -75.03 & -21 & \\
\hline \multirow{2}{*}{ Quercitrin } & 447.1 & 300.5 & 150 & -90 & -10 & -36 & -11 & 16.3 \\
\hline & & 270.8 & 150 & -90 & -10 & -66 & -41 & \\
\hline \multirow[t]{3}{*}{ Hesperidin } & 609.2 & 300.8 & 150 & -85 & -10 & -46 & -49 & 16.5 \\
\hline & & 285.8 & 150 & -85 & -10 & -70 & -41 & \\
\hline & & 163.5 & 150 & -85 & -10 & -88 & -25 & \\
\hline \multirow{3}{*}{ Neohesperidin } & 609.2 & 300.7 & 150 & -115 & -10 & -56 & -9.32 & 16.9 \\
\hline & & 285.7 & 150 & -115 & -10 & -72.89 & -42.3 & \\
\hline & & 150.5 & 150 & -115 & -10 & -100 & -21 & \\
\hline \multirow[t]{2}{*}{ Didymin } & 593.2 & 284.8 & 150 & -100 & -10 & -48 & -45 & 19.8 \\
\hline & & 164 & 150 & -100 & -10 & -92 & -27 & \\
\hline \multirow{2}{*}{ Poncirin } & 593.3 & 284.8 & 150 & -120 & -10 & -54 & -9 & 20.0 \\
\hline & & 163.4 & 150 & -120 & -10 & -92 & -23 & \\
\hline \multirow[t]{2}{*}{ Luteolin } & 285 & 150.6 & 150 & -85 & -10 & -41.6 & -20.9 & 20.5 \\
\hline & & 132.9 & 150 & -85 & -10 & -54 & -17 & \\
\hline \multirow[t]{3}{*}{ Quercetin } & 301 & 150.8 & 150 & -75 & -10 & -36 & -21 & 20.7 \\
\hline & & 178.7 & 150 & -75 & -10 & -28 & -27 & \\
\hline & & 120.8 & 150 & -75 & -10 & -44 & -16.3 & \\
\hline \multirow[t]{2}{*}{ Kaempferol } & 284.9 & 92.9 & 150 & -80 & -10 & -51.4 & -14.1 & 23.1 \\
\hline & & 116.88 & 150 & -80 & -10 & -67 & -18.8 & \\
\hline \multirow{3}{*}{ Naringenin } & 271 & 150.7 & 150 & -60 & -10 & -28.87 & -23.14 & 23.2 \\
\hline & & 118.7 & 150 & -60 & -10 & -40.9 & -16.7 & \\
\hline & & 106.6 & 150 & -60 & -10 & -37.8 & -16.9 & \\
\hline Analyte & {$[\mathrm{M}-\mathrm{H}]^{+}$} & {$[\mathrm{M}-\mathrm{H}]^{+} \rightarrow \mathrm{m} / \mathrm{z}$} & DW & DP & EP & CE & CXP & Rt (min) \\
\hline \multirow[t]{3}{*}{ Bergapten } & 217.2 & 202 & 150 & 64.1 & 10 & 30.9 & 10.9 & 25.8 \\
\hline & & 174.3 & 150 & 64.1 & 10 & 41.4 & 6.1 & \\
\hline & & 90.1 & 150 & 64.1 & 10 & 57.9 & 3.1 & \\
\hline \multirow[t]{2}{*}{ Limonin } & 471.2 & 425.3 & 150 & 71 & 10 & 28.6 & 22 & 26.7 \\
\hline & & 161.1 & 150 & 71 & 10 & 37.7 & 12.7 & \\
\hline \multirow[t]{2}{*}{ Nobiletin } & 403.1 & 373.1 & 150 & 61 & 10 & 41 & 14 & 26.7 \\
\hline & & 388.1 & 150 & 61 & 10 & 31 & 16 & \\
\hline \multirow[t]{2}{*}{ Nomilin } & 515.2 & 469.3 & 150 & 44.9 & 10 & 20.18 & 11.4 & 27.9 \\
\hline & & 161.1 & 150 & 44.9 & 10 & 35.1 & 11.2 & \\
\hline \multirow[t]{3}{*}{ Tangeretin } & 372.97 & 343 & 150 & 71 & 10 & 39 & 26 & 28.4 \\
\hline & & 297.1 & 150 & 71 & 10 & 47 & 10 & \\
\hline & & 211.1 & 150 & 71 & 10 & 60.87 & 7.3 & \\
\hline
\end{tabular}

$\mathrm{M}$, molecular weight; $\mathrm{m} / \mathrm{z}$, selected ions monitored; DW, dwell time in msec; DP, declustering potential; EP, entrance potential; CE, collision energy; CXP, collision cell exit potential; and Rt, retention time. 
<smiles>COc1ccc(-c2cc(=O)c3c(OC)c(OC)c(OC)c(O)c3o2)cc1</smiles><smiles>O=C1CC(c2ccc(O)cc2)Oc2cc(O)cc(Br)c21</smiles>

(b)<smiles>COc1ccc(-c2cc(=O)c3c(OC)c(OC)c(OC)c(OC)c3o2)cc1O</smiles><smiles>O=C(O)/C=C/c1ccc(O)c(O)c1</smiles><smiles>C[C@@H]1C[C@](C)(O)C[C@@H](OC(=O)/C=C/c2ccc(Br)c(O)c2)[C@H]1O</smiles><smiles>O=c1cc(-c2ccc(Br)c(Cl)c2)oc2cc(O)cc(Cl)c12</smiles>

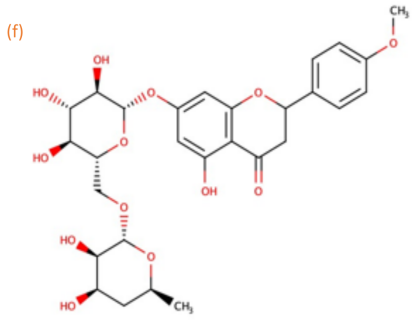

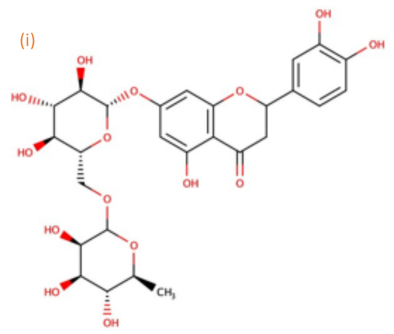

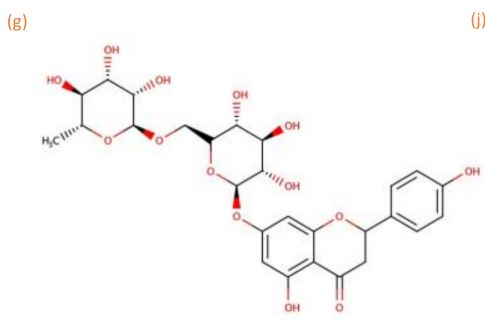

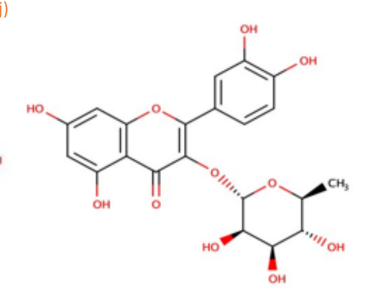<smiles>CCC1OC(Cc2cc(C)c3c(c2)OC(c2ccc(F)c(F)c2)CC3=O)C(O)[C@@H](C)[C@H]1C</smiles><smiles>CC1CC(C)C(C)C(C)C1C</smiles>

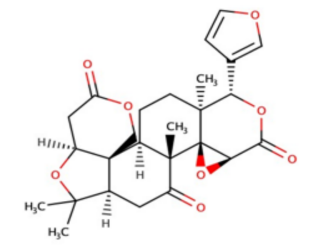

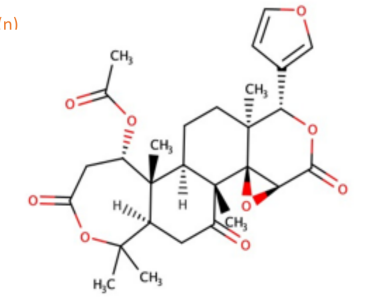

Figure 1. Structure and classification of polyphenols quantified in commercial varieties of mandarin leaves. Polymethoxyflavones, tangeretin (a) and nobiletin (b); hydroxycinnamic acids, caffeic acid (c) and chlorogenic acid (d); flavanones, naringenin (e), didymin (f), narirutin (g), eriocitrin (i), and hesperidin (k); flavone, luteolin (h); flavonol, quercitrin (j); and limonoids, limonin (m) and nomilin (n).

\subsection{Chemotaxonomic Characterization of Bearing Branches}

Leaves from bearing branches of the four studied genotypes contained high concentrations of hesperidin $\left(2824.43 \mu \mathrm{g} / \mathrm{g}{ }^{*}\right)$, followed by nobiletin $\left(583.71 \mu \mathrm{g} / \mathrm{g}{ }^{*}\right)$, tangeretin $\left(326.60 \mu \mathrm{g} / \mathrm{g}^{*}\right)$, narirutin $\left(63.22 \mu \mathrm{g} / \mathrm{g}^{*}\right)$, and eriocitrin $\left(37.23 \mu \mathrm{g} / \mathrm{g}^{*}\right)$. Meanwhile, the most abundant limonoid was limonin $(0.69 \mu \mathrm{g} / \mathrm{g} *)$. The phytochemical concentration of each variety is displayed in Table 2. * Average of the four genotypes.

Table 2. Identified phytochemicals in bearing leaf of 'Ellendale' (B-END), 'Willowleaf' (B-WL), 'Page' (B-PG), and 'Satsuma' (B-SAT) and their concentration expressed in $\mu \mathrm{g} / \mathrm{g}$ of dried leaf.

\begin{tabular}{ccccc}
\hline Compound & B-SAT & B-END & B-WL & B-PG \\
\cline { 2 - 5 } & \multicolumn{4}{c}{$(\mu \mathbf{g} / \mathbf{g}){ }^{*}$} \\
\hline Chlorogenic Acid & $3.88^{\mathrm{b}} \pm 0.40$ & $3.53^{\mathrm{b}} \pm 0.37$ & $6.70^{\mathrm{a}} \pm 0.78$ & $5.04^{\mathrm{b}} \pm 1.39$ \\
Caffeic Acid & $3.87^{\mathrm{b}} \pm 0.21$ & $4.34^{\mathrm{ab}} \pm 0.23$ & $5.38^{\mathrm{a}} \pm 1.05$ & $5.18^{\mathrm{a}} \pm 0.51$ \\
Didymin & $10.57^{\mathrm{b}} \pm 1.11$ & $20.19^{\mathrm{a}} \pm 3.27$ & $3.30^{\mathrm{c}} \pm 0.43$ & $21.17^{\mathrm{a}} \pm 3.76$ \\
Hesperidin & $3008.58^{\mathrm{a}} \pm 151.89$ & $2512.39^{\mathrm{b}} \pm 182.61$ & $2624.31^{\mathrm{b}} \pm 114.09$ & $3152.43^{\mathrm{a}} \pm 298.13$ \\
Eriocitrin & $47.93^{\mathrm{a}} \pm 6.42$ & $13.90^{\mathrm{c}} \pm 1.19$ & $29.85^{\mathrm{b}} \pm 2.44$ & $57.24^{\mathrm{a}} \pm 8.02$ \\
Luteolin & $1.45^{\mathrm{a}} \pm 0.05$ & $1.21^{\mathrm{a}} \pm 0.08$ & $1.81^{\mathrm{a}} \pm 0.28$ & $2.31^{\mathrm{a}} \pm 1.26$ \\
Naringenin & $0.38^{\mathrm{b}} \pm 0.02$ & $0.57^{\mathrm{a}} \pm 0.01$ & $0.34^{\mathrm{b}} \pm 0.01$ & $0.63^{\mathrm{a}} \pm 0.15$ \\
Narirutin & $87.03^{\mathrm{a}} \pm 12.68$ & $50.08^{\mathrm{b}} \pm 7.58$ & $17.58^{\mathrm{c}} \pm 7.58$ & $98.20^{\mathrm{a}} \pm 14.35$ \\
Quercitrin & $2.29^{\mathrm{b}} \pm 0.07$ & $2.43^{\mathrm{b}} \pm 0.13$ & $2.98^{\mathrm{ab}} \pm 0.55$ & $3.69^{\mathrm{a}} \pm 0.61$ \\
Nobiletin & $258.17^{\mathrm{c}} \pm 16.48$ & $1121.36^{\mathrm{a}} \pm 34.94$ & $747.15^{\mathrm{b}} \pm 55.16$ & $208.17^{\mathrm{c}} \pm 13.63$ \\
Tangeretin & $64.96^{\mathrm{c}} \pm 6.15$ & $731.28^{\mathrm{a}} \pm 30.15$ & $475.84^{\mathrm{b}} \pm 56.24$ & $34.34^{\mathrm{c}} \pm 5.01$ \\
Limonin & $0.45^{\mathrm{c}} \pm 0.04$ & $0.88^{\mathrm{a}} \pm 0.08$ & $0.72^{\mathrm{b}} \pm 0.12$ & $0.76^{\mathrm{ab}} \pm 0.08$ \\
Nomilin & $0.42^{\mathrm{b}} \pm 0.03$ & $0.62^{\mathrm{a}} \pm 0.08$ & $0.57^{\mathrm{ab}} \pm 0.13$ & $0.52^{\mathrm{ab}} \pm 0.04$ \\
\hline
\end{tabular}

* In each row, means (5 replicates) \pm SD followed by the same letter do not differ significantly using significance t-test with Bonferroni correction, $p \leq 0.05$. 
A PCA was performed to check the grouping of the samples and detect similarities and differences between the four varieties. Figure 2a shows the 2D plot of the PCA, where PC1 and PC2 explain $97.7 \%$ of the total data variance. It shows a good classification of all genotypes, with 'Page' and 'Satsuma' being the ones that have the most similarities between each other.

a

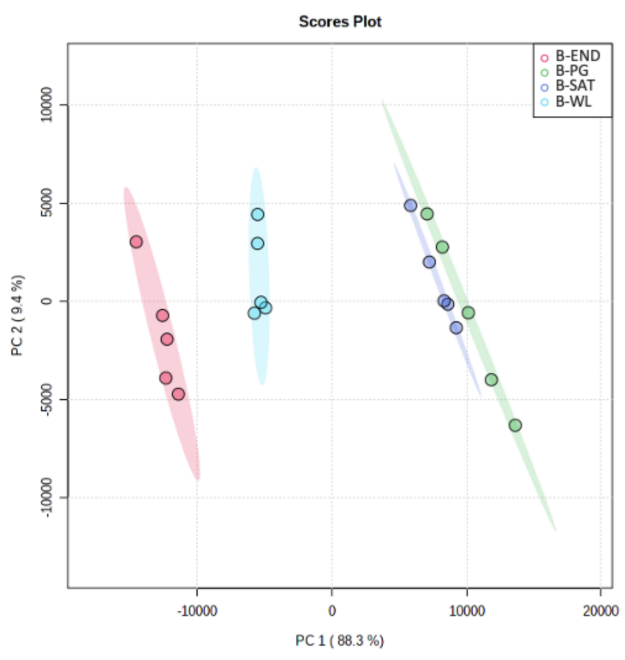

b

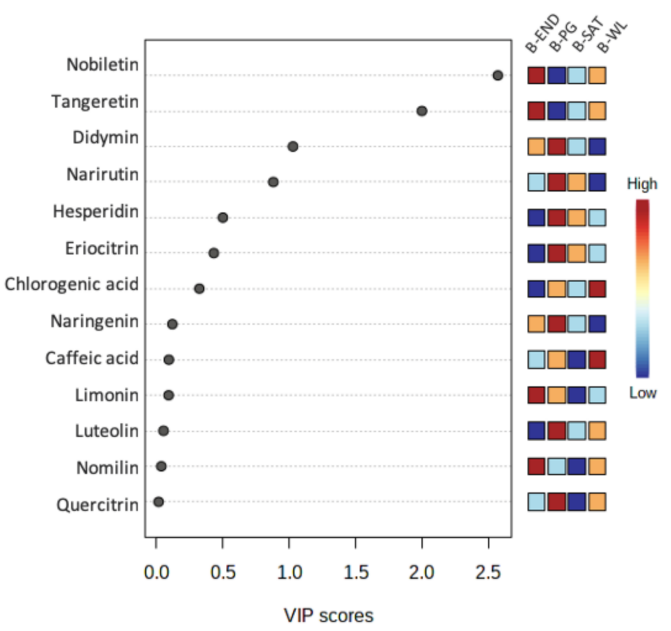

Figure 2. (a) PCA plot of the four varieties of mandarin leaf at a bearing stage 'Ellendale' (B-END), 'Willowleaf' (B-WL), 'Page' (B-PG), and 'Satsuma' (B-SAT); (b) VIP scores of the PLS-DA performed over the four varieties of bearing mandarin leaves.

After performing a PLS-DA, the top three scores of the Variables Importance in the Projection (VIP) are nobiletin for the differentiation of END-PG, tangeretin for END-PG, and didymin for PG-WL (Figure $2 b$ ).

\subsection{Chemotaxonomic Characterization of Non-Bearing Branches}

The same polyphenols and limonoids found in bearing branches were found in the non-bearing branches' leaves but with different concentrations (Table 3). Narirutin was the principal flavonoid with the highest concentration for non-bearing 'Page' and 'Willowleaf' $(42198.36 \mu \mathrm{g} / \mathrm{g}$ in NB-PG and $10049.66 \mu \mathrm{g} / \mathrm{g}$ in NB-WL, respectively). Hesperidin is the most abundant flavonoid for the non-bearing 'Satsuma' and 'Ellendale' $(2591.54 \mu \mathrm{g} / \mathrm{g}$ in NB-SAT and $2433.21 \mu \mathrm{g} / \mathrm{g}$ in NB-END, respectively), as shown also in bearing branches.

Table 3. Identified phytochemicals in non-bearing leaves of 'Ellendale' (NB-END), 'Willowleaf' (NB-WL), 'Page' (NB-PG), and 'Satsuma' (NB-SAT) and their concentration expressed in $\mu \mathrm{g} / \mathrm{g}$ of dried leaf.

\begin{tabular}{ccccc}
\hline & NB-SAT & NB-END & NB-WL & NB-PG \\
\cline { 2 - 5 } Compound & \multicolumn{3}{c}{$(\mu \mathrm{g} / \mathbf{g})^{*}$} \\
\hline Chlorogenic Acid & $126.02^{\mathrm{a}} \pm 6.40$ & $11.31^{\mathrm{b}} \pm 0.62$ & $6.75^{\mathrm{b}} \pm 1.41$ & $6.35^{\mathrm{b}} \pm 1.50$ \\
Caffeic Acid & $2.32^{\mathrm{a}} \pm 0.12$ & $2.00^{\mathrm{b}} \pm 0.09$ & $0.12^{\mathrm{c}} \pm 0.04$ & $0.04^{\mathrm{c}} \pm 0.02^{\mathrm{y}}$ \\
Didymin & $6.44^{\mathrm{bc}} \pm 0.47$ & $17.40^{\mathrm{a}} \pm 2.97$ & $5.03^{\mathrm{c}} \pm 2.56$ & $14.07^{\mathrm{ab}} \pm 8.77$ \\
Hesperidin & $2591.54^{\mathrm{b}} \pm 55.63$ & $2433.21^{\mathrm{b}} \pm 179.79$ & $4224.72^{\mathrm{a}} \pm 450.98$ & $4270.21^{\mathrm{a}} \pm 400.09$ \\
Eriocitrin & $132.39^{\mathrm{a}} \pm 15.01$ & $17.09^{\mathrm{d}} \pm 1.82$ & $39.62^{\mathrm{c}} \pm 5.34$ & $69.98^{\mathrm{b}} \pm 17.91$ \\
Luteolin & $3.16^{\mathrm{c}} \pm 0.60$ & $2.13^{\mathrm{c}} \pm 0.15$ & $2659.07^{\mathrm{a}} \pm 267.40$ & $2023.38^{\mathrm{b}} \pm 121.10$ \\
Naringenin & $0.32^{\mathrm{b}} \pm 0.02$ & $0.68^{\mathrm{b}} \pm 0.12$ & $509.61^{\mathrm{a}} \pm 100.14$ & $574.03^{\mathrm{a}} \pm 101.15$ \\
Narirutin & $97.45^{\mathrm{c}} \pm 8.08$ & $62.85^{\mathrm{c}} \pm 5.04$ & $10049.66^{\mathrm{b}} \pm 1005.64$ & $42198.36^{\mathrm{a}} \pm 3700.22$ \\
Quercitrin & $2.80^{\mathrm{b}} \pm 0.21$ & $2.44^{\mathrm{b}} \pm 0.16$ & $350.39^{\mathrm{a}} \pm 122.31$ & $362.45^{\mathrm{a}} \pm 50.83$ \\
Nobiletin & $290.48^{\mathrm{e}} \pm 24.07$ & $1257.23^{\mathrm{a}} \pm 87.18$ & $1028.88^{\mathrm{b}} \pm 151.80$ & $228.71^{\mathrm{c}} \pm 12.86$ \\
Tangeretin & $99.89^{\mathrm{c}} \pm 10.05$ & $517.97^{\mathrm{a}} \pm 78.41$ & $347.23^{\mathrm{b}} \pm 82.59$ & $33.27^{\mathrm{c}} \pm 5.98$ \\
Limonin & $3.40^{\mathrm{a}} \pm 0.44$ & $0.77^{\mathrm{c}} \pm 0.05$ & $1.30^{\mathrm{b}} \pm 0.09$ & $1.28^{\mathrm{b}} \pm 0.03$ \\
Nomilin & $0.6^{\mathrm{ab}} \pm 0.01$ & $0.54^{\mathrm{b}} \pm 0.05$ & $0.19^{\mathrm{a}} \pm 0.14$ & $0.66^{\mathrm{ab}} \pm 0.03$ \\
\hline
\end{tabular}

${ }^{*}$ In each row, means (5 replicates) \pm SD followed by the same letter do not differ significantly using significance t-test with Bonferroni correction, $p \leq 0.05$. 
Non-bearing branches of 'Page' were characterized by the highest luteolin, narirutin, and quercitrin levels, a situation which was also observed in 'Willowleaf'. In 'Satsuma', eriocitrin and chlorogenic acid were characteristic of this genotype, whereas in 'Ellendale', the polymethoxyflavones tangeretin and nobiletin were the metabolites that characterize the leaves of non-bearing branches.

In the PCA plot, it can be seen that the four genotypes are well classified from each other. PC1 and PC2 accounted for the $97.3 \%$ of the observed variance (Figure 3a). 'Willowleaf' and 'Page' showed more dispersion compared to the other two varieties due to the variability in the levels of some flavonoids.

a

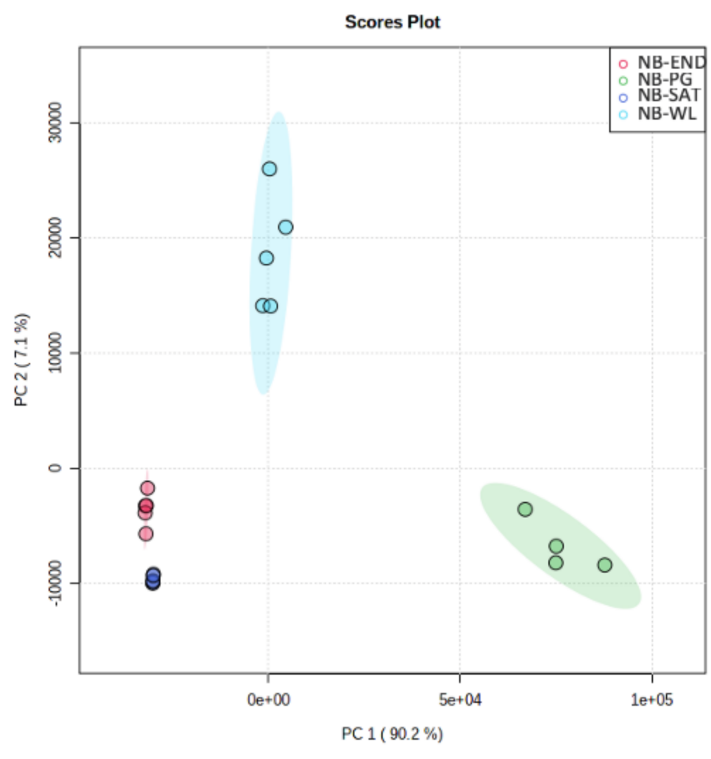

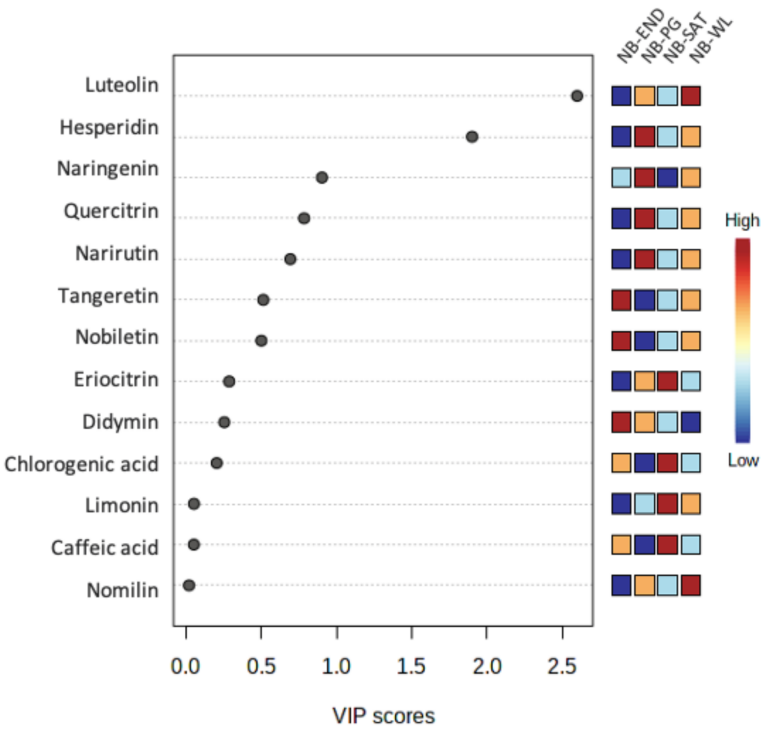

Figure 3. (a) PCA plot of the four varieties of mandarin leaf in their non-bearing stage: 'Ellendale' (NB-END), 'Willowleaf' (NB-WL), 'Page' (NB-PG), and 'Satsuma' (NB-SAT); (b) PLS-DA VIP scores.

The concentration of both polymethoxyflavones were different, being highest to lowest: NB-END, NB-WL, NB-SAT, and NB-PG. The flavanone hesperidin was highest for the duad WL-PG; the same behavior was observed for flavanones naringin and naringenin, flavonols, and flavones. Didymin had high concentration values in NB-END and NB-PG, but not in NB-WL and NB-SAT. Hydroxycinnamic acids are present in the highest concentration in NB-SAT variety (Figure 3a, Tables 2 and 3).

The most important compounds according to VIP scores include luteolin, hesperidin, and naringenin. (Figure 3b). 'Willowleaf' has the highest concentration of luteolin, and 'Page' of hesperidin and naringenin.

\subsection{Metobolites' Profile Comparison between Leaves from Bearing and Non-Bearing Branches}

The chemotaxonomic characterization of the four genotypes in both bearing stages ("on" and "off") allowed the identification of characteristic compounds that could differentiate between bearing stages. In order to determine if there is a significant difference between the means of these two groups, a Wilcoxon/Mann-Whitney test for each compound between bearing and non-bearing leaves was performed for each genotype. Figure 4 shows that nobiletin is not useful in differentiating between bearing and non-bearing stages, for any genotype. Hesperidin, luteolin, naringenin, narirutin, and quercitrin are the compounds that could differentiate between stages; however, it depends on the genotype considered. For example, narirutin is useful for differentiating all the genotypes except for 'Satsuma'. Using this test, a set of compounds could not be selected to classify both stages for all the varieties, due to their high variability. Instead, a pairwise study of the "on"-"off" physiological situations of each cultivar showed significant differences between them. 
These facts could be ascribed to the different genetic origins of each genotype. Interestingly, there were significant differences in eriocitrin levels between both physiological stages for three of the genotypes excepting 'Satsuma'.

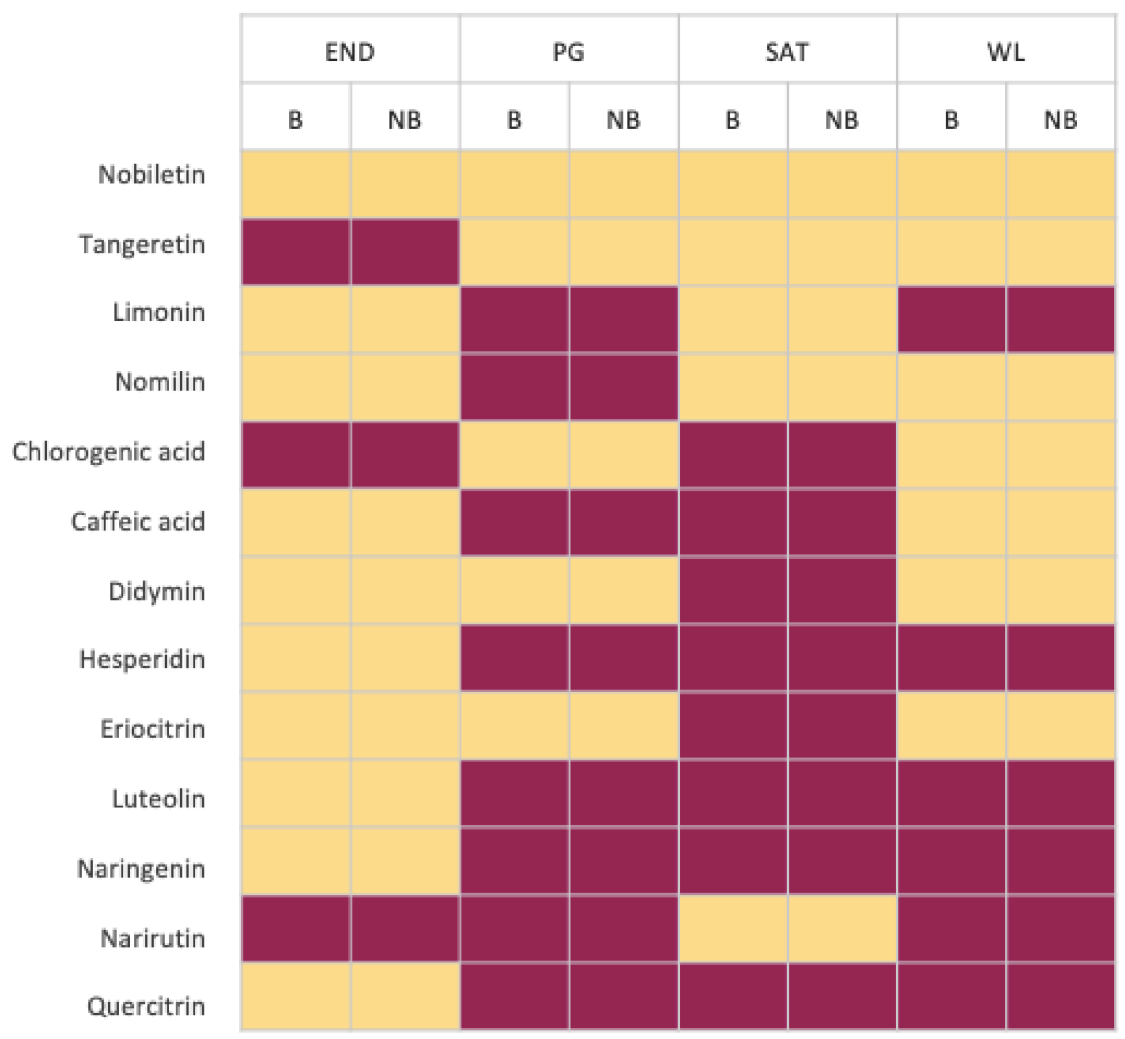

Figure 4. Visual representation of Wilcoxon test for determination of significant differences between bearing and non-bearing stages, for each compound and each variety. References: 'Ellendale' (END), 'Page' (PG), 'Satsuma' (SAT), 'Willowleaf' (WL), bearing stage (B), non-bearing stage (NB), _ means does not differ significantly using Wilcoxon test, $p \leq 0.05$, and $\square$ means differs significantly using Wilcoxon test, $p \leq 0.05$.

In order to identify the compounds responsible for the differentiation of stages in all the genotypes, other statistical approaches were performed and, thus, a Heatmap based on a Student's t-test was developed and shown in Figure 5a. Narirutin, hesperidin, luteolin, naringenin, and quercitrin could be used to differentiate both stages in 'Page' and 'Willowleaf', as the non-bearing samples have the highest concentration of these compounds. Interestingly, caffeic acid is a common marker for the bearing branches of the other varieties. In Figure 5b, the VIP scores of the PLS-DA performed are shown. This analysis allowed the identification of the compounds responsible for the classification of the "on" an "off" bearing stages. Narirutin and luteolin are the variables with the highest VIP scores, and could be identified as candidate markers of alternate bearing.

'Willowleaf' and 'Page' showed clear differences in the concentration level of some metabolites between "on" and "off" phases, that could easily distinguish both bearing stages. Quercitrin presented two orders of magnitude higher concentration in "off" than in "on" phase. The ratio hesperidin/narirutin could be indicative of the bearing stage of 'Willowleaf' and 'Page', when it is $<1$ the tree is in the non-bearing phase, whereas when the quotient is $>10$, the tree is at the bearing stage. 


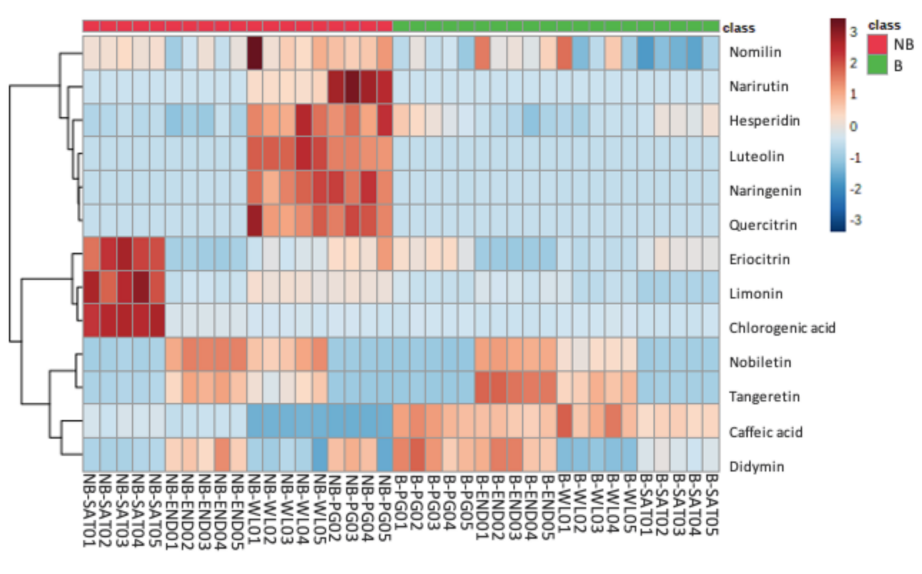

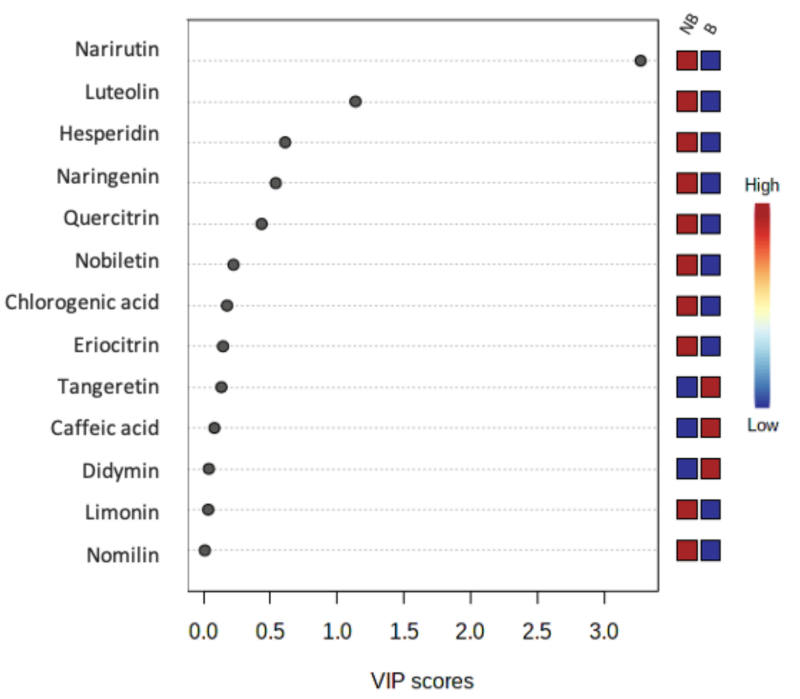

Figure 5. (a) Heatmap of bearing and non-bearing leaf samples of the four varieties of mandarin: 'Ellendale' (END), 'Willowleaf' (WL), 'Page' (PG), and 'Satsuma' (SAT); (b) VIP scores of the PLS-DA performed to identify the metabolites that differentiate between both bearing stages.

Some differences in the metabolites' profile detected between "on" and "off" mandarin branches are due to the position of the biosynthetic pathways of the prevailing metabolites found in them. For instance, nomilin is the biosynthetic precursor of Limonin [37,38]. Limonoids have not been studied as markers of alternate bearing in mandarin trees. In the case of the limonoid biosynthetic pathway the sequence Nomilin-Limonin reaches higher concentration levels during the non-bearing phase, indicating the possibility that the tree is preparing to protect itself against pest and insects before the flowering stage. Naringenin, which is the first polycyclic flavonoid skeleton, is found in trace amounts in leaves arising from non-bearing branches of cvs. 'Satsuma' and 'Ellendale', but in significant levels in 'Page' and "Willowleaf' cultivars. In bearing branches naringenin was found in very low quantities in all four varieties. In the former case, the biosynthetic pathway to flavanones is favored by $7-\mathrm{O}$-glycosylation with hesperoside, a disaccharide [ $1 \rightarrow 6]$ glucose-rhamnose producing narirutin, which is the prevailing flavanone in non-bearing leaves of 'Page' and 'Willowleaf' [39,40].

From naringenin, hesperidin and narirutin are formed. Narirutin seems to be a marker of non-bearing trees, as it showed significant differences between bearing and non-bearing samples, particularly in 'Page' and 'Willowleaf'. The biosynthesis of both hesperosides (Figure 6) goes through the 7-O-glycosidation of naringenin, which is then specifically glycosidated in the position 6-O of the sugar moiety by a rhamonsyl residue. In the non-bearing phase, when the tree is recovering after the energy sink caused by fruiting, the glycosidation reaction yielded higher levels of the naringenin glycosides. When the fruit is developing, the metabolism is fully expressed and active, and all the naringenin is driven through the oxydation-methylation pathway to hesperidin, the most ubiquitous citrus flavonoid. 


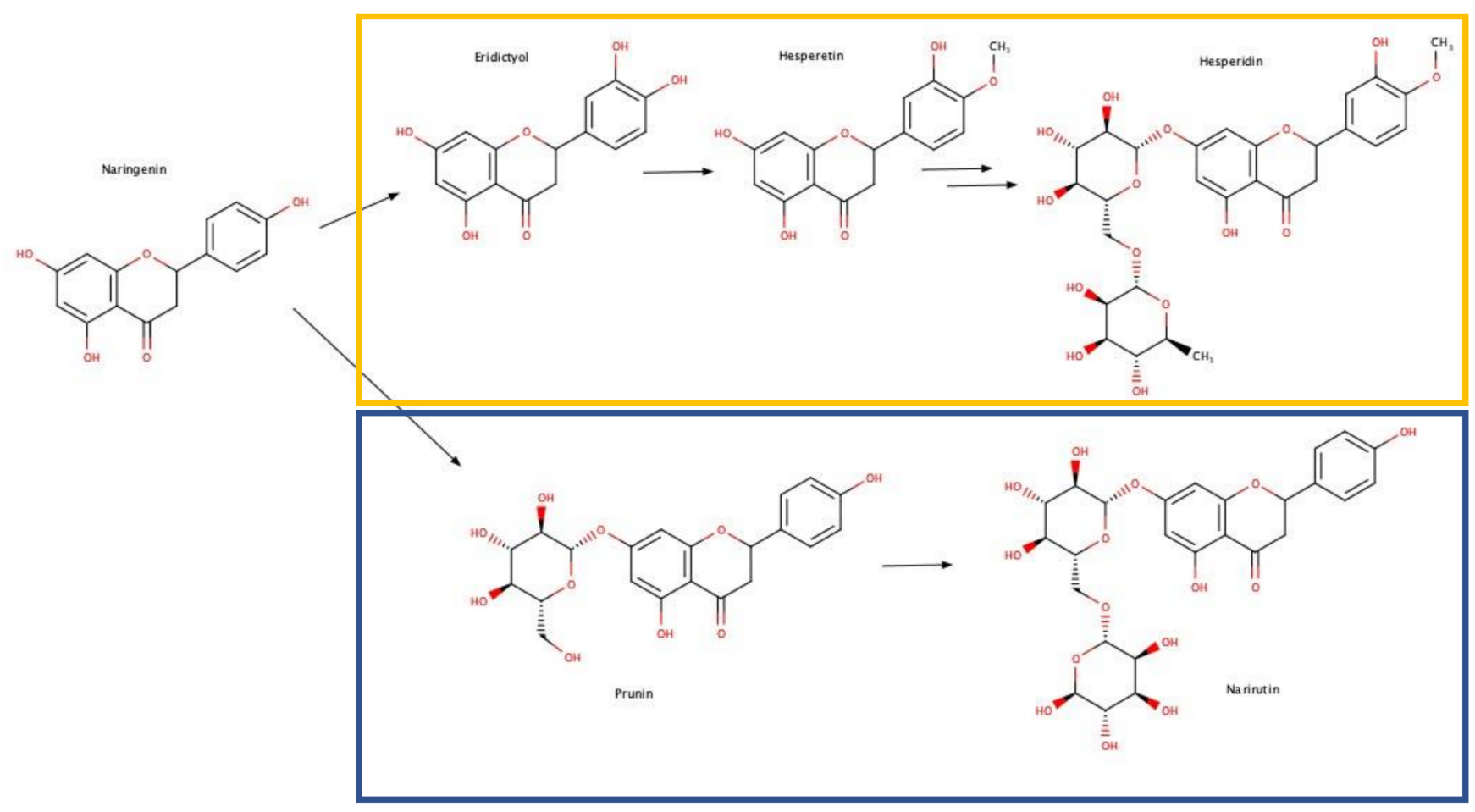

Figure 6. Biosynthetic pathway from naringenin to hesperidin through eriodictyol and hesperitin. The aglycone is then glycosidated with glucose and rhamnose. In a similar sequence, intact naringenin is glycosidated two times; first, to form prunin, which is later glycosidated by the 6-O-rhamnosyl transferase to form narirutin.

Interestingly Mou et al. [41], in an attempt to decipher the flavonoid biosynthetic pathway in C. reticulata, did not describe the pathway leading to narirutin, but they described the naringenin-naringin route. The mandarin species studied produce the tasteless narirutin instead of the bitter naringin. The difference between both compounds is the union between the rhamnose and the glucose moiety, in narirutin the link is $(1 \rightarrow 6)$ (rutinoside), whereas in naringin the link is $(1 \rightarrow 2)$ (neohesperoside).

Another route downstream of the flavonoid biosynthesis in mandarin trees leads to the polymethoxyflavones (PMF), suggested as markers of bearing stages [42,43]. Luteolin, an acknowledged precursor of PMF is also distinctive polyphenol of the non-bearing phase.

The general trend discussed above, allowed the assessment of qualitative and quantitative differences between the four genotypes, depending on the physiological status of the branch. Flavonoid biosynthesis in citrus is regulated by a combination of environmental, genetic, and hormonal factors. As the former is the same for all the individuals in this study, the two latter variables are the ones responsible for the observed differences. It has been accepted that in "off" branches, buds are directed to morph to leaves instead of flowers, enhancing primary and secondary metabolism, which confirms the general trend identified by Shalom et al. [2], that flavonoid biosynthesis is enhanced during the "off" phase in 'Murcott' mandarins. They found that the expression of all the enzymes of the flavonoid pathway were significatively higher in "off" branches, as well as the expression of mRNA from FT, AP1, and LFY related genes, which was correlated with the up-regulation effect of these genes in the "off" phase. The obtained results of our study in four different mandarin cultivars are in accordance with the expression of the genes described by Shalom [2]. Moreover, high levels of abscisic acid, which is high in buds, leaves, and fruits during autumn in 'Murcott' ("on" phase) and other alternating citrus varieties, have been shown to up regulate the flavonoid biosynthesis in another non-climateric fruits, such as blueberries and tomatoes $[44,45]$. 
Furthermore, Narirutin is identified as a possible marker of the "on/off" phase as it presents statistically different levels in all varieties during both stages. The only exception is 'Satsuma', a variety that does not present the typical alternate bearing behavior as exhibited by the rest of the studied varieties.

\section{Conclusions}

A specific analytical protocol using LC-MS-(QqQ)-MS, applying different acquisition modes, permitted the unambiguous determination of 13 secondary metabolites in leaves of mandarin trees. A chemosystematic study of the profile of these metabolites in leaves from non-bearing ("off") and bearing ("on") mandarin branches belonging to four different genotypes was performed. The different genotypes could be chemotaxonomically distinguished from each other at both developmental stages using multivariate data analysis and the representative metabolites were identified.

This study allowed the differentiation between leaves from non-bearing and bearing branches. Leaves from both physiological stages accumulated limonin, but nomilin showed an increased leaf concentration in non-bearing branches compared to bearing ones. "On" and "off" 'Willowleaf' and 'Page' mandarin trees can be distinguished due to the high narirutin content in leaves of non-bearing branches, and an easy relationship has been proposed to define each phase. One of the most important observations found is the increase of Narirutin content in non-bearing leaves for genotypes that show a typical alternate bearing behavior which could lead to the use of this compound as a biomarker of the stage of the branch. The presence of flavonoids as markers of the different physiological stages of mandarin trees also hints to possible new ways of crop management. Future studies should be performed following the developed methodology to control the levels of these compounds, specially Narirutin, during the ontogeny of mandarin branches along the plant growth.

The results reported in the present research can contribute towards a useful technology for growers and scientists to determine the physiological stage of a tree depicting the transition from "off" to "on" phase in Citrus.

Supplementary Materials: The following are available online at https: / www.mdpi.com/article / 10.3390/agronomy12010121/s1, Table S1: Target compounds selected for the analysis, Figure S1: Chromatogram of the mix of standards at $800 \mathrm{~g} / \mathrm{L}$ injected into the LC-MS/MS in negative (Top) and positive 46 (Bottom) mode, and Figure S2: Chromatograms of 'Willowleaf' genotype at non-bearing ("off") stage (A) and at a bearing ("on") stage (B) in negative acquisition mode.

Author Contributions: Conceptualization, H.H. and I.M.; methodology, C.R.C. and V.V.; validation, C.R.C. and I.M.; formal analysis, C.R.C., I.M. and V.V.; investigation, C.R.C., I.M. and H.H.; writingoriginal draft preparation, C.R.C. and I.M.; writing-review and editing, H.H. and F.R.; supervision, H.H. and M.V.C.; project administration, H.H. and F.R.; funding acquisition, F.R. All authors have read and agreed to the published version of the manuscript.

Funding: This research was funded by INIA through the L4 funding program, CSIC grant number 1822, the Agencia Nacional de Investigación e Innovación grant number POS_NAC_2017_1_140316, and the Programa de Desarrollo de las Ciencias Básicas.

Data Availability Statement: The data presented in this study are available on request from the corresponding author.

Acknowledgments: We would like to thank Natalia Besil for the assistance during the optimization of the MS analyses.

Conflicts of Interest: The authors declare no conflict of interest. 


\section{References}

1. FAOSTAT. Available online: http://www.fao.org/faostat/en/\#data/QCL/visualize (accessed on 5 October 2021).

2. Shalom, L.; Samuels, S.; Zur, N.; Shlizerman, L.; Zemach, H.; Weissberg, M.; Ophir, R.; Blumwald, E.; Sadka, A. Alternate Bearing in Citrus: Changes in the Expression of Flowering Control Genes and in Global Gene Expression in ON- versus OFF-Crop Trees. PLOS ONE 2012, 7, e46930. [CrossRef]

3. Agust, M.; Almela, V.; Pons, J. Effects of girdling on alternate bearing in citrus. J. Hortic. Sci. 1992, 67, 203-210. [CrossRef]

4. Talon, M.; Tadeo, F.R.; Ben-Cheikh, W.; Gomez-Cadenas, A.; Mehouachi, J.; Pérez-Botella, J.; Primo-Millo, E. Hormonal regulation of fruit set and abscission in citrus: Classical concepts and new Evidence. Acta Hortic. 1998, 463, 209-217. [CrossRef]

5. Bower, J.P.; Cutting, J.G.M.; Lovatt, C.J.; Blanke, M.M. Interaction of plant growth regulator and carbohydrate in flowering and fruit set. Acta Hortic. 1990, 425-434. [CrossRef]

6. Davenport, T.L. Citrus Flowering. In Horticultural Reviews; John Wiley \& Sons, Inc.: Hoboken, NJ, USA, 2011 ; pp. $349-408$.

7. Peña, L.; Martín-Trillo, M.; Juárez, J.; Pina, J.A.; Navarro, L.; Martínez-Zapater, J.M. Constitutive expression of Arabidopsis LEAFY or APETALA1 genes in citrus reduces their generation time. Nat. Biotechnol. 2001, 19, 263-267. [CrossRef]

8. Pillitteri, L.J.; Lovatt, C.J.; Walling, L.L. Isolation and characterization of LEAFY and APETALA1 homologues from Citrus sinensis L. Osbeck "Washington". J. Am. Soc. Hortic. Sci. 2004, 129, 846-856. [CrossRef]

9. Araki, T. Transition from vegetative to reproductive phase. Curr. Opin. Plant Biol. 2001, 4, 63-68. [CrossRef]

10. Moss, G.I. Effect of fruit on flowering in relation to biennial bearing in sweet orange (Citrus sinensis). J. Hortic. Sci. 1971, 46, 177-184. [CrossRef]

11. Wada, K.C.; Takeno, K. Stress-induced flowering. Plant Signal. Behav. 2010, 5, 944-947. [CrossRef] [PubMed]

12. Takeno, K. Stress-Induced Flowering. Abiotic Stress Responses Plants 2012, 331-345. [CrossRef]

13. Kazan, K.; Lyons, R. The link between flowering time and stress tolerance. J. Exp. Bot. 2016, 67, 47-60. [CrossRef]

14. Zagoskina, N.V.; Kazantseva, V.V.; Fesenko, A.N.; Shirokova, A.V. Accumulation of Phenolic Compounds at the Initial Steps of Ontogenesis of Fagopyrum esculentum Plants That Differ in Their Ploidy Levels. Biol. Bull. 2018, 45, 171-178. [CrossRef]

15. Coley, P.D.; Bryant, J.P.; Chapin, F.S. Resource Availability and Plant Antiherbivore Defense. Science 1985, 230, 895-899. [CrossRef]

16. Waterman, P.; Mole, S. Analysis of Phenolic Plant Metabolites; Blackwell Scientific Publications: Oxford, UK, 1994.

17. Grace, S.G.; Logan, B.A. Energy Dissipation and Radical Scavenging by the Plant Phenylpropanoid Pathway. Philos. Trans. R. Soc. Lond. B Biol. Sci. 2000, 355, 1499-1510. [CrossRef]

18. Rivas, F.; Fornes, F.; Agustí, M. Girdling induces oxidative damage and triggers enzymatic and non-enzymatic antioxidative defences in Citrus leaves. Environ. Exp. Bot. 2008, 64, 256-263. [CrossRef]

19. Panche, A.N.; Diwan, A.D.; Chandra, S.R. Flavonoids: An overview. J. Nutr. Sci. 2016, 5, 1-15. [CrossRef]

20. Cheynier, V. Polyphenols in foods are more complex than often thought. Am. J. Clin. Nutr. 2005, 81, 223S-229S. [CrossRef] [PubMed]

21. McClure, J.W. Physiology and Functions of Flavonoids. In The Flavonoids; Harbone, J.B., Mabry, T.J., Mabry, H., Eds.; Springer: Boston, MA, USA, 1975; pp. 970-1055.

22. Gualdani, R.; Cavalluzzi, M.; Lentini, G.; Habtemariam, S. The Chemistry and Pharmacology of Citrus Limonoids. Molecules 2016, 21, 1530. [CrossRef]

23. Shi, Y.S.; Zhang, Y.; Li, H.T.; Wu, C.H.; El-Seedi, H.R.; Ye, W.K.; Wang, Z.W.; Li, C.B.; Zhang, X.F.; Kai, G.Y. Limonoids from Citrus: Chemistry, anti-tumor potential, and other bioactivities. J. Funct. Foods 2020, 75, 104213. [CrossRef]

24. Roy, A.; Saraf, S. Limonoids: Overview of Significant Bioactive Triterpenes Distributed in Plants Kingdom. Biol. Pharm. Bull. 2006, 29, 191-201. [CrossRef]

25. Hafeez, F.; Akram, W.; Shaalan, E.A.-S. Mosquito larvicidal activity of citrus limonoids against Aedes albopictus. Parasitol. Res. 2011, 109, 221-229. [CrossRef] [PubMed]

26. Warikoo, R.; Ray, A.; Sandhu, J.K.; Samal, R.; Wahab, N.; Kumar, S. Larvicidal and irritant activities of hexane leaf extracts of Citrus sinensis against dengue vector Aedes aegypti L. Asian Pac. J. Trop. Biomed. 2012, 2, 152-155. [CrossRef]

27. Khan, M.K.; Dangles, O. A comprehensive review on flavanones, the major citrus polyphenols. J. Food Compos. Anal. 2014, 33, 85-104. [CrossRef]

28. Yu, X.; Shi, D.; Zhi, X.; Li, Q.; Yao, X.; Xu, H. Synthesis and quantitative structure-activity relationship (QSAR) study of C7-oxime ester derivatives of obacunone as insecticidal agents. RSC Adv. 2015, 5, 31700-31707. [CrossRef]

29. Hasegawa, S.; Berhow, M.A.; Manners, G.D. Citrus limonoid research: An overview. ACS Symp. Ser. 2000, 758, 1-8. [CrossRef]

30. Celano, R.; Campone, L.; Pagano, I.; Carabetta, S.; Di Sanzo, R.; Rastrelli, L.; Piccinelli, A.L.; Russo, M. Characterisation of nutraceutical compounds from different parts of particular species of Citrus sinensis 'Ovale Calabrese' by UHPLC-UV-ESI-HRMS. Nat. Prod. Res. 2019, 33, 244-251. [CrossRef]

31. Russo, M.; Arigò, A.; Calabrò, M.L.; Farnetti, S.; Mondello, L.; Dugo, P. Bergamot (Citrus bergamia Risso) as a source of nutraceuticals: Limonoids and flavonoids. J. Funct. Foods 2016, 20, 10-19. [CrossRef]

32. Wang, F.; Yu, X.; Liu, X.; Shen, W.; Zhu, S.; Zhao, X. Temporal and spatial variations on accumulation of nomilin and limonin in the pummelos. Plant Physiol. Biochem. 2016, 106, 23-29. [CrossRef] [PubMed]

33. Roberts, L.D.; Souza, A.L.; Gerszten, R.E.; Clish, C.B. Targeted metabolomics. Curr. Protoc. Mol. Biol. 2012, 1, 30.2.1-30.2.24. [CrossRef] 
34. Xi, W.; Zhang, Y.; Sun, Y.; Shen, Y.; Ye, X.; Zhou, Z. Phenolic composition of Chinese wild mandarin (Citrus reticulata Balnco.) pulps and their antioxidant properties. Ind. Crops Prod. 2014, 52, 466-474. [CrossRef]

35. Safdar, M.N.; Kausar, T.; Jabbar, S.; Mumtaz, A.; Ahad, K.; Saddozai, A.A. Extraction and quantification of polyphenols from kinnow (Citrus reticulate L.) peel using ultrasound and maceration techniques. J. Food Drug Anal. 2017, 25, 488-500. [CrossRef] [PubMed]

36. Pang, Z.; Chong, J.; Zhou, G.; de Lima Morais, D.A.; Chang, L.; Barrette, M.; Gauthier, C.; Jacques, P.-É.; Li, S.; Xia, J. MetaboAnalyst 5.0: Narrowing the gap between raw spectra and functional insights. Nucleic Acids Res. 2021, 49, 388-396. [CrossRef] [PubMed]

37. Ou, P.; Hasegawa, S.; Herman, Z.; Fong, C.H. Limonoid biosynthesis in the stem of Citrus limon. Phytochemistry 1988, 27, 115-118. [CrossRef]

38. Gerolino, E.; Chierrito, T.; Santana-Filho, A.; Rorigues, S.; Gonçalves, R.; Oliveira, A. Evaluation of limonoid production in suspension cell culture of Citrus sinensis. Rev. Bras. Farmacogn. 2015, 56. [CrossRef]

39. Berim, A.; Gang, D.R. Methoxylated flavones: Occurrence, importance, biosynthesis. Phytochem. Rev. 2016, 15, 363-390. [CrossRef]

40. Abad-García, B.; Garmón-Lobato, S.; Berrueta, L.A.; Gallo, B.; Vicente, F. On line characterization of 58 phenolic compounds in Citrus fruit juices from Spanish cultivars by high-performance liquid chromatography with photodiode-array detection coupled to electrospray ionization triple quadrupole mass spectrometry. Talanta 2012, 99, 213-224. [CrossRef]

41. Mou, J.; Zhang, Z.; Qiu, H.; Lu, Y.; Zhu, X.; Fan, Z.; Zhang, Q.; Ye, J.; Fernie, A.R.; Cheng, Y.; et al. Multiomics-based dissection of citrus flavonoid metabolism using a Citrus reticulata $\times$ Poncirus trifoliata population. Hortic. Res. 2021, 8, 56. [CrossRef] [PubMed]

42. Zhao, C.; Wang, F.; Lian, Y.; Xiao, H.; Zheng, J. Biosynthesis of citrus flavonoids and their health effects. Crit. Rev. Food Sci. Nutr. 2020, 60, 566-583. [CrossRef]

43. Frydman, A.; Weisshaus, O.; Bar-Peled, M.; Huhman, D.V.; Sumner, L.W.; Marin, F.R.; Lewinsohn, E.; Fluhr, R.; Gressel, J.; Eyal, Y. Citrus fruit bitter flavors: Isolation and functional characterization of the gene $\mathrm{Cm1}, 2 \mathrm{RhaT}$ encoding a 1,2 rhamnosyltransferase, a key enzyme in the biosynthesis of the bitter flavonoids of citrus. Plant J. 2004, 40, 88-100. [CrossRef]

44. Chung, S.W.; Yu, D.J.; Oh, H.D.; Ahn, J.H.; Huh, J.H.; Lee, H.J. Transcriptional regulation of abscisic acid biosynthesis and signal transduction, and anthocyanin biosynthesis in 'Bluecrop' highbush blueberry fruit during ripening. PLoS ONE 2019, 14, e0220015. [CrossRef]

45. Monselise, S.P.; Goldschmidt, E.E. Alternate bearing in citrus and ways of control. In Proceedings of the International Society of Citriculture, Tokyo, Japan, 9-12 November 1981; pp. 239-242. 